\title{
Numerical Evaluation of Contributions of Pollutant Sources Extracted by Constrained Oblique Rotational Factor Analysis for Precipitation Data. Extraction of Features of Precipitations at Hyogo and Akita Areas
}

\author{
Toru Ozeki*†, Kunichika KoIDE*, Nobuaki OGawa**, Tetsuya AdzuHata**, \\ Masahiro KAJIKAWA** and Takashi KIMoto*** \\ *Hyogo University of Teacher Education, \\ Shimokume 942-1, Yashiro-cho, Kato-gun, Hyogo 673-14, Japan \\ ** Department of Chemistry, Faculty of Education, Akita University, \\ Tegata Gakuencho, Akita 010, Japan \\ *** Research Institute of OceanoChemistry, 5-19, Funahashi-cho, Tennoji, Osaka 543, Japan
}

\begin{abstract}
A statistical method developed by our group, "the constrained oblique rotational factor analysis" enables feature reduction and grouping of the pollutant sources in precipitations from their chemical compositions. A study applied to the precipitations has indicated the necessity of the numerical evaluation of contributions of the extracted sources. In this paper, a procedure for the numerical evaluation is demonstrated; and, as one application, the precipitations collected in Hyogo prefecture are compared with those in Akita prefecture. The analysis has proposed that an ion-balance check of the extracted pollutant source gives a simple criterion about how many pollutant sources should be extracted. As a result, the causes of lowering of the $\mathrm{pH}$ of the precipitation of these two areas are explained by two sources: 1) an acidic source with sulfuric acid predominant brought over the Sea of Japan from China by winter monsoons; and 2) another acidic source with sulfuric acid and nitric acid predominant emitted domestically. The seasonal changes of acidity of the precipitation of Japan depend upon the amounts of these two contributions.
\end{abstract}

Keywords Factor analysis, environmental analysis, acid rain, precipitation, pollutant source

Recently, acid rain is receiving global interest because it causes damage of plants as well as artificial constructions such as buildings. ${ }^{1}$ The acid rain is a contaminated precipitation absorbing various pollutants in the air. These pollutants contaminate precipitations in a form of a combination of salts, such as sea-salt particles, acidic pollutants formed by photochemical reactions of $\mathrm{NO}_{x}$ and $\mathrm{SO}_{x}$, and so on. The chemical compositions of precipitations are very complicated so that feature reduction of the pollutants is required. The purpose of our research is to propose a means disclosing 1) what are the pollutant (substances), 2) how much they pollute (amounts), and 3) how they pollute (mechanisms). In this paper, parts 1) and 2) are discussed.

In order to accomplish our purpose, we have modified one of the multivariate methods, factor analysis, previously used for the analysis of environmental samples. $^{2-7}$ When the conventional factor analyses such as the principal component analysis (PCA) with the Varimax rotation were used, the interpretation of the character of the extracted source is sometimes difficult; especially for its acidity (or basicity) evaluation (whether it works as acid, base or neutral substance), because the methods assume an orthogonal relationship among the extracted sources. We have incorporated a special constraint to enable this evaluation. A newly developed method by our group, "a constrained oblique rotational factor analysis" has been published elsewhere. ${ }^{8}$ It has demonstrated that the method can extract a simplified feature of pollutant substances in precipitations, qualitatively. However, a study applied to the precipitations collected in the Hyogo area makes us notice the necessity of the numerical evaluation of contributions of the extracted sources. In this paper, a procedure for the numerical evaluation is demonstrated; and, as an application, the precipitations collected in Hyogo prefecture are compared with those in Akita prefecture; these areas are considered as typical representatives of Japan in climatic and geometrical features since the Island of Japan is long in latitude, as shown in Fig. 1. This paper will also propose that an ion-balance check of the extracted pollutant source gives a simple criterion about how many pollutant sources at most can be extracted reasonably. 
The Island of Japan

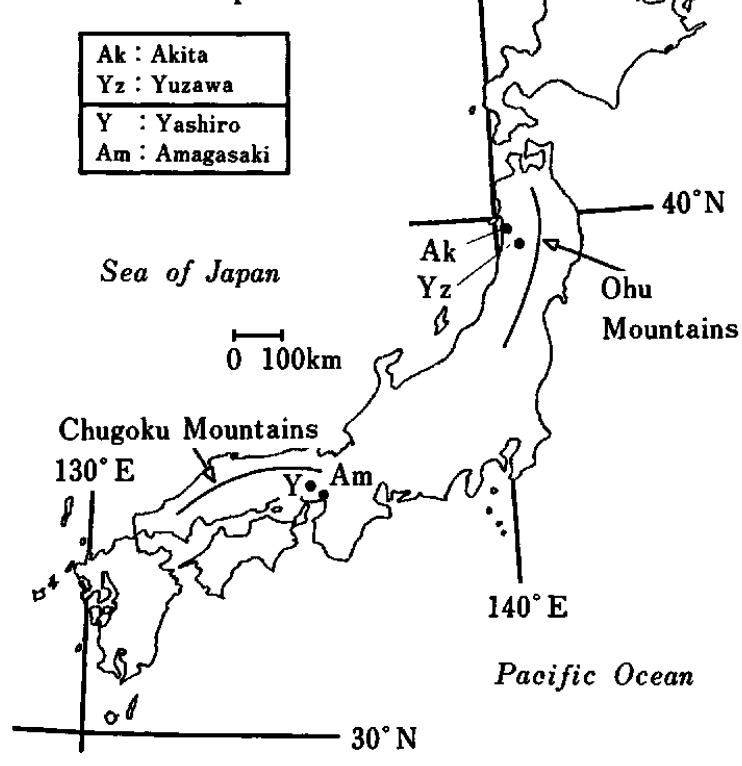

Fig. 1 Locations of sampling places.

\section{Experimental}

\section{Sampling and chemical analysis of precipitations}

Two data-sets were analyzed in this paper as application examples. The first data-set is one collected and chemically analyzed at the Hyogo University of Teacher Education, and the second is one collected and analyzed at Akita University. The locations of the sampling points are shown in Fig. 1.

The sampling points belonging to Hyogo: Y (Yashiro town) + Am (Amagasaki city) are located in the midst of the Island of Japan, and they are close to the Pacific Ocean in front of the Chugoku Mountains. The sampling point $Y$ consists of five places. Precipitations from October 1991 to September 1992 were collected. At the points $\mathrm{Y}$ and $\mathrm{Am}$, beginning $1 \mathrm{~mm}$ rains and event based all-rains were collected. For chemical analysis, an ion chromatograph (Yokokawa-Hokushin IC-100) was used for anion analysis, and an atomic absorption photometer was used for cation analysis, except for hydrogen ions and ammonium ions. The ammonium ion concentration was measured by the indophenol method using a UV-Vis photometer (Shimadzu UV-210); and the hydrogen ion concentration was calculated from the $\mathrm{pH}$ value measured by a $\mathrm{pH}$ meter (Horiba $\mathrm{M}-8 \mathrm{~L}$ ).

On the other hand, the points belonging to Akita: Ak (Akita city) +Yz (Yuzawa city) are located in the northern part of the Island of Japan. They are close to the Sea of Japan in front of the Ohu Mountains. The sampling point Ak consists of two places. Precipitations including both rains and snows were collected from January to March of 1992, and from March 1993 to March 1994. The sampling point $\mathrm{Yz}$ is about $50 \mathrm{~km}$ southeastern from Akita city. At the $\mathrm{Yz}$, precipitations from January to March of 1992, and those from January to March of 1994 were collected. At these points, the precipitations were collected on a day-after-day basis so that containers were changed every morning. The snow collected in the container was melted and was kept as liquid. For chemical analysis, an ion chromatograph (Toa Denpa, ICA-5000) was used for both cations and anions. Hydrogen ion concentration was calculated from $\mathrm{pH}$ values measured by a $\mathrm{pH}$ meter (Toa Denpa HM-30S). The methods of chemical analyses mentioned above were carried out according to the suggestions of the Japan Environment Agency. ${ }^{9}$

In the following factor analysis, the chemically analyzed data of precipitations, whose ion-balances (the ratio of the sum of equivalents of anions to that of cations) are from 1.2 to $0.833(1 / 1.2)$ namely $20 \%$ deviation, were utilized in order to exclude the data of bad quality. The numbers of the data fulfilling the above criterion against the number of the total data are as follows: Ak, 153/221 (69.2\%); Yz, 79/89 (88.8\%); Y, $330 / 511$ (64.6\%); Am, 62/113 (54.9\%). Most of the precipitations of poor ion-balance are those with $\mathrm{pH}$ values higher than 5.6. The reason seems to be that bicarbonate ion $\mathrm{HCO}_{3}{ }^{-}$has not been quantified. Some of the statistical quantities of the data used for the present analysis are shown in Table 1.

The differences in the sampling methods (day-afterday sampling, beginning $1 \mathrm{~mm}$ sampling, event based sampling) seem not to affect our conclusions as to the character of pollutant species in precipitations.

\section{Procedures of data analysis}

As mentioned in the introduction section, the purpose of this data analysis is to disclose 1) what are the pollutants (substances) and 2) how much they pollute (amounts). The initial part of the following analysis (Step 1 and 2) as to the first part 1) has been already reported $^{8}$, but the outline of the procedure has to be briefly mentioned here with some modified points. The steps related to the second part 2 ) will be mentioned in Steps 3 and 4 . The equivalent unit is used to describe concentrations of ion throughout this paper.

[Step 1 Principal Component Analysis (PCA)]

This step is essentially the same as the PCA. ${ }^{10-13}$ For the data analysis, values of equivalents of nine ions $\left(\mathrm{H}^{+}\right.$, $\left.\mathrm{Na}^{+}, \mathrm{K}^{+}, \mathrm{NH}_{4}^{+}, \mathrm{Mg}^{2+}, \mathrm{Ca}^{2+}, \mathrm{SO}_{4}{ }^{2-}, \mathrm{NO}_{3}{ }^{-}, \mathrm{Cl}^{-}\right)$were used. A data matrix $\boldsymbol{D}$ is constructed, in which the chemical composition of every precipitation sample is aligned as a row vector. An element $\mathrm{d}_{i j}$ is the equivalent of the $j$-th ion in the $i$-th sample.

1-1 A covariance matrix $Z$ is calculated:

$$
Z=t D D
$$

1-2 An eigenvalue matrix $\boldsymbol{E}$ and an eigenvector matrix $\boldsymbol{Q}$ are calculated by using the Jacobi method:

$$
Q E^{\top} Q=Z
$$

1-3 The number of factors (the number of the independent pollutant sources) is assumed; a new criterion for 
Table 1 Statistical quantities of ions $\left(\mu \mathrm{eq} / \mathrm{dm}^{-3}\right)$

\begin{tabular}{|c|c|c|c|c|c|c|c|c|c|c|c|c|}
\hline Location & $\mathrm{pH}$ & $\begin{array}{c}\mathrm{EC} / \\
\mu \mathrm{S} \mathrm{cm}^{-1}\end{array}$ & $\begin{array}{c}\text { Amount } / \\
\mathrm{mm}\end{array}$ & {$\left[\mathrm{Cl}^{-}\right]$} & {$\left[\mathrm{NO}_{3}{ }^{-}\right]$} & {$\left[\mathrm{SO}_{4}{ }^{2-}\right]$} & {$\left[\mathrm{Na}^{+}\right]$} & {$\left[\mathbf{K}^{+}\right]$} & {$\left[\mathrm{Ca}^{2+}\right]$} & {$\left[\mathrm{Mg}^{2+}\right]$} & {$\left[\mathrm{NH}_{4}{ }^{+}\right]$} & {$\left[\mathbf{H}^{+}\right]$} \\
\hline \multicolumn{13}{|c|}{ Y (330 data) } \\
\hline Mean & 4.61 & 61.95 & 8.26 & 106.55 & 72.94 & 173.52 & 85.37 & 19.21 & 89.29 & 28.32 & 76.67 & 64.05 \\
\hline S.D. & 0.74 & 42.54 & 12.31 & 106.33 & 67.36 & 133.43 & 71.54 & 22.68 & 90.58 & 26.64 & 89.38 & 75.30 \\
\hline $\operatorname{Max}$ & 7.01 & 285.00 & 50.00 & 601.40 & 425.40 & 799.00 & 311.40 & 178.00 & 677.80 & 214.20 & 493.00 & 346.74 \\
\hline Min & 3.46 & 3.89 & 1.00 & 2.90 & 1.20 & 9.60 & 0.00 & 0.00 & 0.00 & 0.00 & 0.00 & 0.10 \\
\hline \multicolumn{13}{|c|}{ Am (62 data) } \\
\hline Mean & 5.09 & 47.85 & 11.69 & 117.89 & 55.26 & 138.96 & 70.44 & 11.68 & 112.37 & 32.64 & 61.89 & 25.93 \\
\hline S.D. & 0.78 & 36.68 & 14.40 & 138.49 & 55.12 & 126.54 & 70.62 & 10.84 & 139.69 & 37.44 & 71.78 & 32.77 \\
\hline $\operatorname{Max}$ & 6.65 & 151.00 & 50.00 & 615.30 & 242.20 & 710.60 & 284.00 & 46.00 & 655.40 & 177.40 & 291.50 & 141.25 \\
\hline Min & 3.85 & 5.77 & 1.00 & 5.70 & 5.50 & 11.80 & 5.60 & 0.40 & 6.40 & 1.00 & 0.00 & 0.22 \\
\hline \multicolumn{13}{|c|}{ Ak (153 data) } \\
\hline Mean & 4.88 & 64.50 & 10.27 & 399.28 & 18.93 & 105.50 & 332.14 & 10.34 & 37.03 & 79.04 & 42.84 & 23.73 \\
\hline S.D. & 0.60 & 63.66 & 11.23 & 530.08 & 25.60 & 86.21 & 433.67 & 11.68 & 41.51 & 100.98 & 42.05 & 21.72 \\
\hline Max & 6.70 & 437.00 & 60.45 & 3709.81 & 193.71 & 506.12 & 3023.92 & 76.64 & 244.69 & 693.67 & 352.58 & 131.83 \\
\hline Min & 3.88 & 3.75 & 1.14 & 1.66 & 0.94 & 8.65 & 0.85 & 0.19 & 0.94 & 0.36 & 2.28 & 0.20 \\
\hline \multicolumn{13}{|c|}{ Yz (79 data) } \\
\hline Mean & 5.00 & 50.35 & 9.70 & 326.56 & 11.34 & 76.30 & 276.65 & 9.44 & 26.38 & 62.56 & 30.86 & 14.62 \\
\hline S.D. & 0.44 & 53.93 & 5.87 & 457.44 & 8.84 & 61.52 & 386.39 & 11.27 & 23.49 & 84.05 & 17.08 & 12.00 \\
\hline Max & 6.30 & 393.00 & 28.26 & 3323.39 & 47.54 & 419.32 & 2815.85 & 80.23 & 162.67 & 604.32 & 123.30 & 74.13 \\
\hline Min & 4.13 & 7.53 & 1.39 & 3.35 & 2.13 & 14.12 & 1.82 & 0.62 & 3.68 & 0.00 & 9.85 & 0.50 \\
\hline
\end{tabular}

Mean is the simple arithmatic mean as to rainwater samples with no weight.

the assumption of the number will be mentioned in the later section. The eigenvectors of that number are extracted from the column vectors of the matrix $Q$ and are aligned as row vectors of a composition matrix $C$.

[Step 2 Oblique rotation with partially non-negative constraints]

2-1 Step 1 gives negative values for some elements of the composition matrix $C$ obtained above. An oblique rotation is carried out so that all negative elements of the $C$ are eliminated, except for the elements related to the hydrogen ion, because negative values of the concentration are physically meaningless. The non-negative constraint is excluded from the hydrogen ion in order to evaluate the role of hydroxide ion; if the concentration of the hydrogen ion is negative, then the value can be regarded as the concentration of the hydroxide ion, because the negative value $\left(\mathrm{OH}^{-}\right)$of one pollutant source can compensate the positive value $\left(\mathrm{H}^{+}\right)$of another pollutant source to produce a water molecule during the polluting process.

$$
\mathrm{H}^{+}+\mathrm{OH}^{-}=\mathrm{H}_{2} \mathrm{O}
$$

This approach enables evaluation of acidity (and basicity) of each pollutant source. ${ }^{8}$

2-2 The total concentration of ions in each pollutant source is normalized here; namely, the sum of the absolute values of row elements of the matrix $C$ are normalized so that each pollutant source has the same total equivalent, such as one equivalent.

$$
c_{k j}{ }^{\prime}=c_{k j} /\left(\Sigma_{j}\left|c_{k j}\right|\right)
$$

At this time, the summation is carried out by using the absolute value of the element $c_{k j}$ because the equivalent of
$\left[\mathrm{OH}^{-}\right]$is the negative value of the $\left[\mathrm{H}^{+}\right]$. This procedure gives:

$$
\Sigma_{j}\left|c_{k j}\right|=1
$$

In this treatment, the pollutant source can be regarded as a (solid) mixture of chemicals, in which the sum of the equivalents of the ions is one equivalent. This amount of the pollutant source can be defined as $1 \mathrm{~mol}$. In the following sections the symbol $c_{k j}$ and $C$ are used to denote the $c_{k j}{ }^{\prime}$ and its matrix.

[Step 3 Calculation of the contribution matrix]

One way to calculate the contribution matrix $\boldsymbol{R}$ from the above-obtained composition matrix $C$ is to use the least square criterion:

$$
\boldsymbol{D} \approx \boldsymbol{R} \boldsymbol{C}
$$

Then the following calculation gives an optimum solution:

$$
R=D^{t} C\left(C^{t} C\right)^{-1}
$$

The differences of the elements of the both sides of the Eq. (6) have both signs, positive and negative; and the sum of the elements of the residual matrix $(\boldsymbol{D}-\boldsymbol{R} C)$ is essentially zero, independent of the number of factors. Namely, residuals are regarded as random errors. The matrix $\boldsymbol{R}$ is chosen so as to make the variance minimized. An example of this treatment can be seen in the panel $A$ of Fig. 2: This is the plots of the residuals $(\boldsymbol{D}-\boldsymbol{R} C)$ assuming three factors for the Hyogo data-set. We proposed this approach in the previous paper. ${ }^{8}$ However, now we propose another approach implying that there should be residual sources besides the extracted pollutant sources. 

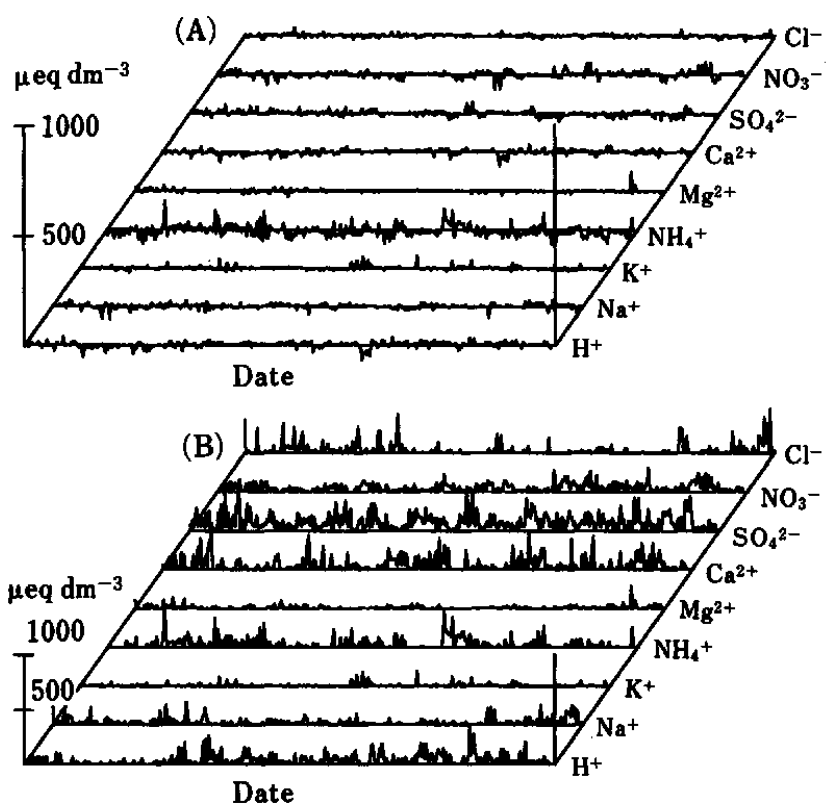

Fig. 2 Comparison of residual errors $(D-R C)$ obtained by using two kinds of $R$ matrixes. (A) The case using $R$ obtained by the least square method; (B) the case using $\boldsymbol{R}_{\mathbf{x}}$ obtained with the inequality constraints, both for the dataset Hyogo with three factors.

We pose an inequality constraint to the elements of $\boldsymbol{R}$, $C$, and $D$, implying that there should be residual sources:

$$
\Sigma_{k} \mathrm{r}_{i k} \mathrm{c}_{k j}<\mathrm{d}_{i j}
$$

In order to obtain a matrix $\boldsymbol{R}$ fulfilling this constraint, the Simplex Tableau Algorithm based on Linear Programming Method can be used. The details on this algorithm can be seen in the references. ${ }^{14,15}$ At panel $B$ of the Fig. 2, the residuals $\left(D-R_{\mathrm{x}} C\right)$ were plotted, where a contribution $\boldsymbol{R}_{\mathrm{x}}$ was the one determined with this inequality constraint. Obviously, all ions have positive residuals. When the number of factors is increased, a new pollutant source is extracted from these residuals. In the following sections the symbol $R$ is used in place of $\boldsymbol{R}_{\mathrm{x}}$.

In the previous section, we said that each pollutant source can be regarded as a (solid) mixture of chemicals, in which the sum of the equivalents of the ions is one equivalent. This amount of the pollutant can be defined as $1 \mathrm{~mol}$. Then, the column elements of the matrix $\boldsymbol{R}$ represents the concentration $\left(\mathrm{mol} \mathrm{dm}^{-3}\right)$ of the pollutant source in each precipitation.

[Step 4 Evaluation of the contributions]

The contribution of each pollutant source to a precipitation sample can be evaluated numerically by using this contribution matrix $R$ obtained above. As the sum $\Sigma_{i} \Sigma_{j} \Sigma_{k}\left(\mathrm{r}_{i k} \mathrm{c}_{k j}\right)$ is less than the sum of the elements of the data matrix $D\left(\Sigma_{i} \Sigma_{j} \mathrm{~d}_{i j}\right)$ due to the above inequality constraints, the total reproduction ratio $T_{\mathrm{rr}}$ is defined as:

$$
T_{\mathrm{rr}}=\Sigma_{i} \Sigma_{j} \Sigma_{k}\left(\mathrm{r}_{i k} \mathrm{c}_{k j}\right) /\left(\Sigma_{i} \Sigma_{j} \mathrm{~d}_{i j}\right)
$$

Now the contribution fraction of the $k$-th source to the $i$ th sample is expressed as:

$$
f_{i, k}=T_{\mathrm{rr}} r_{i k} /\left(\Sigma_{k} r_{i k}\right)
$$

Accordingly, the contribution fraction of the $k$-th source to the total precipitation samples is:

$$
f_{\text {total }, k}=T_{\mathrm{rr}}\left(\Sigma_{i} r_{i k}\right) /\left(\Sigma_{k} \Sigma_{i} r_{i k}\right)
$$

\section{$A$ remark on the scaling procedure using average ion} concentration

In the procedure reported in the previous paper $^{8}$, the elements of the data matrix $D$ were normalized by using the average concentrations of the corresponding ions.

$$
\mathrm{d}_{i j}^{*}=\mathrm{d}_{i j} /<\mathrm{d}_{j}>
$$

Here

$$
<\mathrm{d}_{j}>=\Sigma_{i} \mathrm{~d}_{i j} / n
$$

where $n$ is the number of precipitation samples.

This procedure carries out scaling (or, leveling) of the contribution of every ion used for the analysis to the identical amount. It leads to the result that even an unique source consisting of a minor ion with very small contribution is extracted as an independent pollutant source. A pollutant source specific to potassium ion, which seems to be of bio-mass origin, was an example. ${ }^{8}$ Certainly this scaling procedure works well to find such unique sources due to a minor ion. However, if the purpose of the analysis is to know what are the major pollutant sources and how much they contribute, this scaling procedure overestimates the contribution of such unique sources, but fails to extract the other major sources having more contribution than such a unique source has. In this paper, the scaling procedure was not carried out.

\section{Results and Discussion}

\section{Criterion to find the proper number of pollutant sources}

The procedure mentioned above was applied to the two data-sets Hyogo (Y+Am) and Akita (Ak+Yz). The change of the chemical compositions of the extracted pollutant sources, when the number of factors is increased, is shown in Fig. 3. In Table 2, the contribution fractions of the individual pollutant sources and the values of their ion-balance are shown. When only one source is extracted, the average-like compositions are extracted for both the data-sets. But as the number of factors is increased, the compositions of the extracted sources change, as seen in Fig. 3. When two factors are assumed, sea-salt-like sources (Hyogo-2B, Akita-2A) are extracted. Acidic sources (Hyogo-3B, and Akita-3B) both containing sulfuric acid and nitric acid are extracted when three factors are assumed. The Akita-3C is an alkaline pollutant source because it contains hydrogen ions in negative concentration, meaning $\left[\mathrm{OH}^{-}\right]$. 
1 Hyogo $(\mathrm{Y}+\mathrm{Am})$

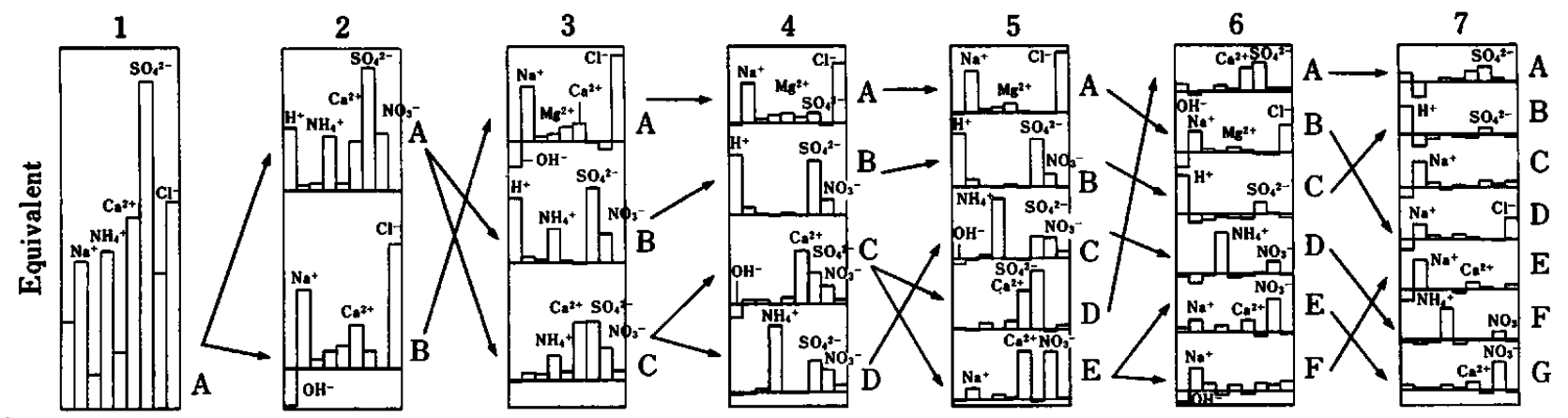

\section{Akita $\left(A k+Y_{z}\right)$}
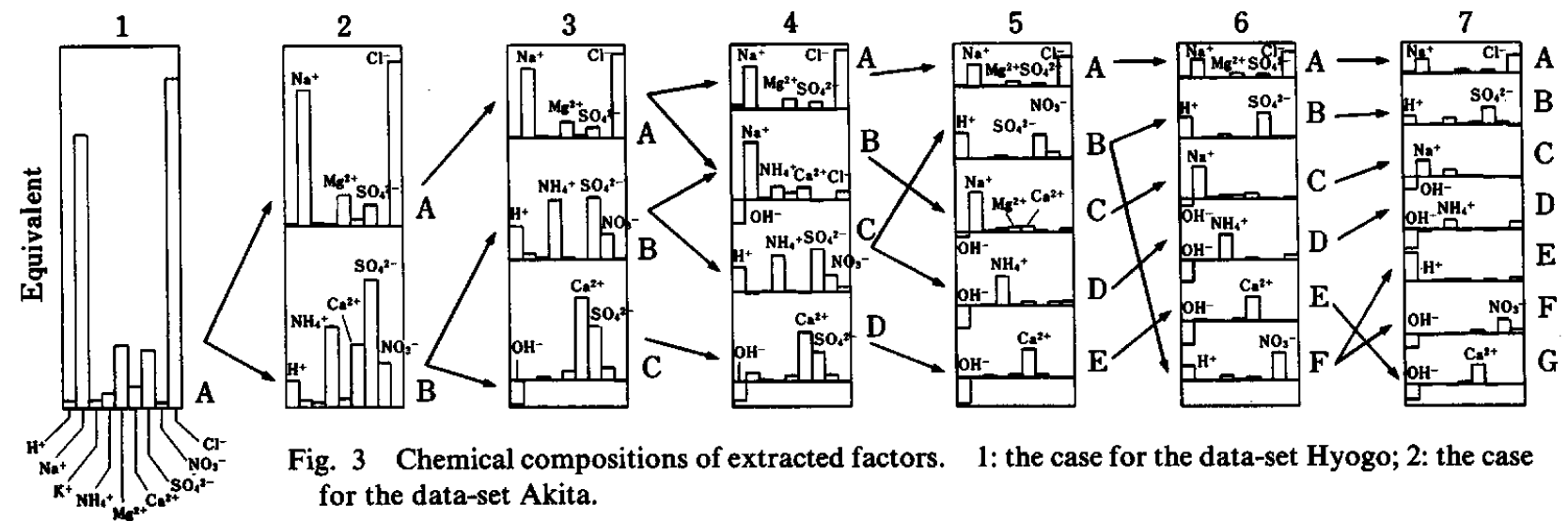

Fig. 3 Chemical compositions of extracted factors. 1: the case for the data-set Hyogo; 2: the case for the data-set Akita.

Table 2 Contribution fractions (cont\%) and the values of ion-balance of the extracted pollutant sources

\begin{tabular}{|c|c|c|c|c|c|c|c|c|c|}
\hline & & \multicolumn{4}{|c|}{ Hyogo (Y+Am) } & \multicolumn{4}{|c|}{ Akita $(A k+Y z)$} \\
\hline & & cont $\%$ & $\Sigma$ cont $\%$ & Ion-balance & $\Sigma(-) / \Sigma(+)$ & cont $\%$ & $\Sigma$ cont $\%$ & Ion-balance & $\Sigma(-) / \Sigma(+)$ \\
\hline 1 & $\mathbf{A}$ & 22.3 & 22.3 & 0.9839 & 0 & 44.9 & 44.9 & 1.0143 & 0 \\
\hline \multirow[t]{2}{*}{2} & A & 25.3 & & 0.9597 & 0 & 65.1 & & 1.0223 & 0 \\
\hline & B & 22.1 & 47.3 & 1.0240 & 0 & 4.2 & 69.3 & 0.8919 & 0 \\
\hline \multirow[t]{3}{*}{3} & $\mathbf{A}$ & 23.9 & & 1.0396 & 0 & 76.8 & & 1.0232 & 0 \\
\hline & B & 19.3 & & 0.9656 & 0 & 6.3 & & 0.8745 & 0 \\
\hline & $\mathrm{C}$ & 15.2 & 58.4 & 0.9623 & 0 & 3.6 & 86.7 & 0.9558 & 0 \\
\hline \multirow[t]{4}{*}{4} & $\mathbf{A}$ & 23.9 & & 1.0374 & 0 & 69.9 & & 1.1592 & 0 \\
\hline & $\mathbf{B}$ & 19.3 & & 0.9892 & 0 & 8.8 & & 0.3293 & $x$ \\
\hline & $\mathrm{C}$ & 14.5 & & 0.9746 & 0 & 6.3 & & 1.0397 & 0 \\
\hline & D & 14.4 & 72.1 & 0.9244 & 0 & 4.2 & 89.2 & 0.8028 & * \\
\hline \multirow[t]{5}{*}{5} & A & 20.6 & & 1.0097 & 0 & 71.2 & & 1.1658 & 0 \\
\hline & B & 18.3 & & 0.9941 & 0 & 8.5 & & 1.1148 & 0 \\
\hline & C & 16.2 & & 0.9155 & 0 & 5.8 & & 0.1797 & $x$ \\
\hline & $\mathrm{D}$ & 15.3 & & 1.1550 & 0 & 3.7 & & 0.8987 & 0 \\
\hline & $\mathbf{E}$ & 9.3 & 79.7 & 0.7361 & $*$ & 3.4 & 92.6 & 0.9098 & 0 \\
\hline \multirow[t]{6}{*}{6} & $\mathbf{A}$ & 22.2 & & 0.9956 & 0 & 69.3 & & 1.1663 & 0 \\
\hline & B & 20.8 & & 1.0880 & 0 & 8.8 & & 1.0897 & 0 \\
\hline & C & 17.1 & & 0.6412 & $x$ & 5.4 & & 0.1906 & $x$ \\
\hline & D & 11.5 & & 1.2132 & $*$ & 4.7 & & 0.9464 & 0 \\
\hline & $\mathrm{E}$ & 8.7 & & 0.6925 & $x$ & 4.1 & & 0.8349 & 0 \\
\hline & $\mathrm{F}$ & 4.6 & 84.9 & 0.7365 & * & 2.2 & 94.5 & 1.1183 & 0 \\
\hline \multirow[t]{7}{*}{7} & A & 24.2 & & 1.6006 & $x$ & 71.4 & & 1.0451 & 0 \\
\hline & B & 15.8 & & 0.6685 & $x$ & 9.5 & & 1.0773 & 0 \\
\hline & $\mathrm{C}$ & 15.1 & & 0.8765 & 0 & 4.4 & & 0.3986 & $x$ \\
\hline & D & 14.6 & & 1.1904 & 0 & 3.9 & & 4.1993 & $x$ \\
\hline & $\mathrm{E}$ & 9.6 & & 0.5100 & $x$ & 2.6 & & 0.1550 & $x$ \\
\hline & F & 6.4 & & 0.4874 & $x$ & 2.1 & & 15.5149 & $x$ \\
\hline & G & 3.1 & 88.8 & 0.9748 & 0 & 1.4 & 95.3 & 0.6628 & $x$ \\
\hline
\end{tabular}

Symbols related to ion-balance: $O$, good (within the limits from 0.833 to 1.2 ratio); $*$, pretty good; $\times$, very bad. 
Here, how to choose the proper number of pollutant sources is very important. For the data-set Hyogo, the ion-balance values of the extracted sources of Table 2 are within or very close to the limits of the original data-set, namely 1.2 to 0.833 up to five sources. It means that they are contributing to the precipitations in the form of salts. However, when six or seven factors are assumed, many of the extracted sources became poor in ionbalance. It means that a salt-like character of the source is decomposed to single ion character. Chemically speaking, the pollutant substance must have neutral charge as a whole. Thus, the check in ion-balance can be used for a criterion for how many factors should be extracted. A similar proposition has been reported by Anttila et al. ${ }^{16}$ From this point of view, the number of the pollutant sources for the data-set Hyogo is five. This selection may cause an objection that the ionbalance value of the source $5 \mathrm{E}$ is not good $(0.7361)$. The sources $5 \mathrm{D}$ and $5 \mathrm{E}$ are decomposed from the source $4 \mathrm{C}$, as seen in Fig. 3. However, these sources 5D and 5E show obvious discrepancies in their seasonal contributions, as mentioned in the later section. Thus the number of factors, five, is selected.

Similarly six factors seems reasonable for the data-set Akita, although the ion-balance ratio of a pollutant source Akita-6C is only 0.1906, which is very bad. However, the predominant ion of this source is sodium ion; and, the ones similar to this source are extracted as Akita-4B and 5C. We have an Asian long-range eolian dust referred to as "kosa" in Japan. It comes from China; and its origin is the Gobi Desert. ${ }^{17}$ Some kinds of dust contain sodium ion; and the major anions are carbonate ion and silicate ion. These anions were not measured in this study. The poor value of the ionbalance may be due to these anions. We think this source should be accounted in as an independent source polluting precipitations for the data-set Akita.

\section{Remarks on the pollutant sources extracted from the data-set Hyogo and their seasonal change}

In Fig. 4, compositions of five pollutant sources extracted from the data-set Hyogo, seasonal changes of their contributions to each precipitation, and the seasonal changes of $\mathrm{pH}$ and hydrogen ion concentration are shown. The compositions of five pollutant sources have the same total equivalents because they are normalized. Since this amount is regarded as $1 \mathrm{~mol}$, the contribution of the pollutant source to each precipitation can be represented by a concentration unit, $\mathrm{mol} \mathrm{dm}^{-3}$. In Fig. 4, the scales on the five contributions are all the same. In this case, the maximum contribution given by the source $A$ was $9.20 \times 10^{-4} \mathrm{~mol} \mathrm{dm}^{-3}$. In Table 3 , the contribution fractions (Eq. (11)) of the extracted five pollutant sources to four kinds of subsets of the data-set Hyogo (2) - (5) are shown with those of the total data-set (1). The subsets are (2) the one consisting of the precipitations collected in summer season (May to September of 1992), (3) the one consisting of the precipitations collected in the other seasons (October of
1991 to April of 1992, denoted as "non-sum"), (4) the one consisting of the precipitations collected by the eventbase sampling (all rain, abbreviated as "A-rain") and (5) the one consisting of the precipitations collected by the beginning $1 \mathrm{~mm}$ height sampling (abbreviated as "B-rain").

The source $\mathrm{A}$ is regarded as a sea-salt origin and its contribution fraction is $20.6 \%$. This source is high from fall to winter (Oct. - Feb.), low in March, high again in April, but very low in summer (May to Aug.). In fall to spring, northwest monsoons bring sea-salt particles from the Sea of Japan. This is the origin of source A in the precipitations of these seasons. From the end of May to August of this year (1992), we had very hot summer days, and most of the precipitations were showers. Showers in summer do not contain any contributions from northwest monsoon, thus they do not contain the sea-salt source so much.

These features are well reflected in numerical values in Table 3. The contribution fraction of the sea-salt source (A) is very high in non-sum seasons $(27.7 \%$ ) but very low in summer (11.7\%). The values of the Table 3 tells us another interesting fact that this source is higher in the B-rains (21.4\%) rather than A-rains (18.1\%). Namely the sea-salt source is precipitated more by the wash-out process than by rain-out process.

The source $\mathrm{B}$ acidifying precipitation has the total contribution of $18.3 \%$; but shows a striking contrast to the sea-salt source A in seasonal pattern; namely high in summer $(26.2 \%)$ and low in non-sum seasons $(12.1 \%)$. This source supplies hydrogen ions; thus, when the contribution fraction of this source is high, the hydrogen concentration is high, and $\mathrm{pH}$ is low. The precipitations ascribed to a shower which precipitates locally contain high contributions of this acidic source. Thus, this source $\mathrm{B}$ causes the lowering of $\mathrm{pH}$ of the summer precipitations. This kind of seasonal change of $\mathrm{pH}$ of precipitation is commonly observed in the areas of Japan which are close to the Pacific Ocean.

We have other three pollutant sources: C, D, E. The discrepancy among these sources can be seen in the numerical values in Table 3. The pollutant sources $\mathrm{C}$, $D$ and $E$ are all precipitated by the wash-out process more than by the rain-out process; they show higher contribution fractions in the B-rains $(17.4,16.2$ and 9.9\%) rather than in the A-rains $(12.8,12.7$ and $7.6 \%)$. The pollutant source $\mathrm{C}$ containing ammonium ion as predominant cation has a higher contribution fraction in summer $(17.7 \%)$ than in the non-sum seasons $(15.0 \%)$. It means some agricultural activity may participate in the emission of this source.

The pollutant sources D and E contain calcium ion as predominant cation; and the anion of the former is sulfate ion, but that of the latter is nitrate ion. Their seasonal contributions are different. The source E containing nitrate ion shows higher contribution fraction in summer $(10.9 \%>8.0 \%)$; but the source $\mathrm{D}$ containing sulfate ion shows higher contribution fraction in the nonsum seasons $(17.0 \%>13.1 \%)$. It means that the nitrate 
Table 3 Contribution fractions of the extracted five pollutant sources in the subsets of the data-set Hyogo

\begin{tabular}{|c|c|c|c|c|c|c|c|}
\hline & & & $\begin{array}{c}(1) \\
\text { Total data-set } \\
(392)^{\mathrm{a}}\end{array}$ & $\begin{array}{c}(2) \\
92 / 5-92 / 9 \text { (summer) } \\
(179)\end{array}$ & $\begin{array}{c}(3) \\
91 / 10-92 / 4 \text { (non-sum) } \\
(213)\end{array}$ & $\begin{array}{l}(4) \\
\text { A-rain } \\
(189)\end{array}$ & $\begin{array}{l}(5) \\
\text { B-rain } \\
(203)\end{array}$ \\
\hline $5 \mathrm{~A}$ & $\mathrm{Na}^{+}, \mathrm{Mg}^{2+}$ & $\mathrm{Cl}^{-}$ & 20.6 & 11.7. & 27.7 & 18.1 & 21.4 \\
\hline $5 \mathrm{~B}$ & $\mathbf{H}^{+}$ & $\mathrm{NO}_{3}{ }^{-}, \mathrm{SO}_{4}{ }^{2-}$ & 18.3 & 26.1 & 12.1 & 23.9 & 16.4 \\
\hline $5 C$ & $\mathrm{NH}_{4}{ }^{+}$ & $\mathrm{NO}_{3}{ }^{-}, \mathrm{SO}_{4}{ }^{2-}$ & 16.2 & 17.7 & 15.0 & 12.8 & 17.4 \\
\hline $5 D$ & $\mathrm{Ca}^{2+}$ & $\mathrm{SO}_{4}{ }^{2-}$ & 15.3 & 13.1 & 17.0 & 12.7 & 16.2 \\
\hline $5 \mathrm{E}$ & $\mathrm{Ca}^{2+}$ & $\mathrm{NO}_{3}^{-}$ & $\begin{array}{c}9.3 \\
(79.7)(\%)\end{array}$ & $\begin{array}{c}10.9 \\
(79.5)(\%)\end{array}$ & $\begin{array}{c}8.0 \\
(79.8)(\%)\end{array}$ & $\begin{array}{c}7.6 \\
(75.1)(\%)\end{array}$ & $\begin{array}{c}9.9 \\
(81.3)(\%)\end{array}$ \\
\hline
\end{tabular}

a. Number of samples.
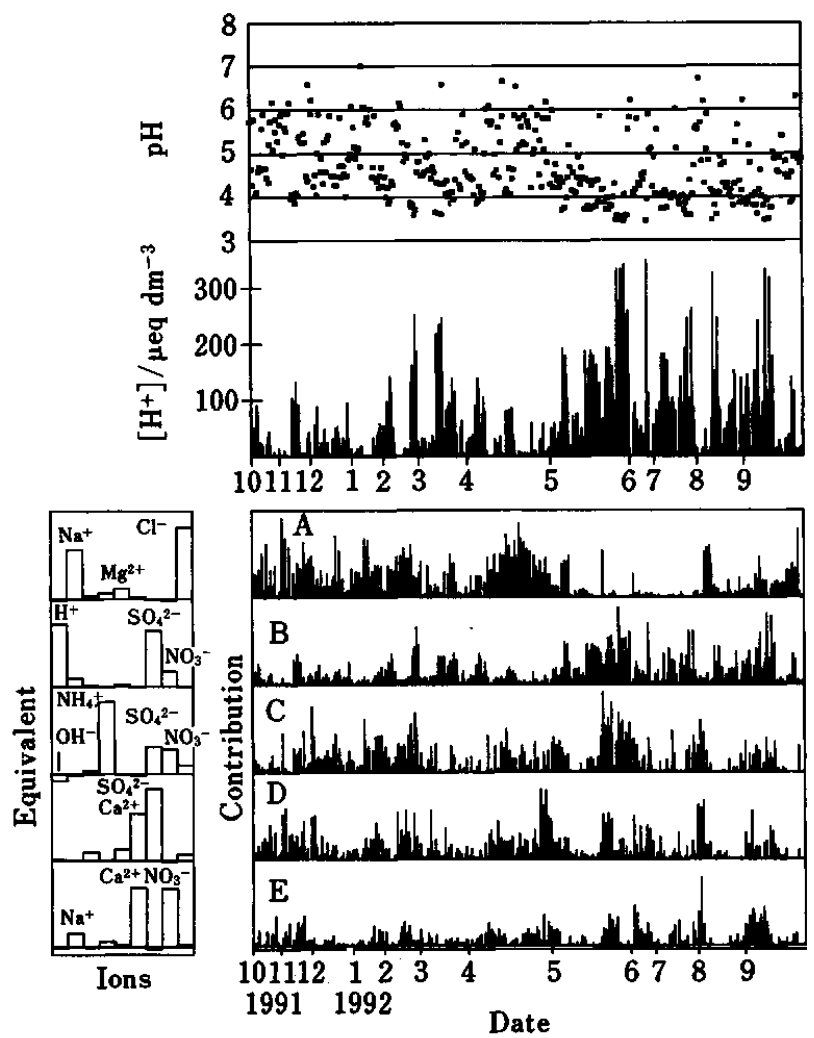

Fig. 4 Chemical compositions of five pollutant sources and their contributions to precipitations collected at Hyogo $(\mathrm{Y}+\mathrm{Am})$. See the text as to the scales of compositions and contributions. Also, refer to Table 2, the 5-factor case of Hyogo.

ion is domestically produced by some photochemical reactions induced by the intense sunshine of summer; but the sulfate ion is brought by the northwest monsoon (fall, winter, to spring) coming from China. As a total, these five pollutant sources contribute $79.7 \%$ to the pollutant substances contained in the precipitations of the data-set Hyogo.

Remarks on the pollutant sources extracted from the data-set Akita and their seasonal change

In Fig. 5, compositions of six pollutant sources ex- tracted from the data-set Akita, seasonal changes of their contributions to each precipitation, and the seasonal changes of $\mathrm{pH}$ and hydrogen ion concentration are shown. In this figure, contribution scales of the sources $B-E$ are ten times that of the source $A$; and that of the source $F$ is twenty times that of the $A$. The maximum contribution of the source $A$ is $2.37 \times 10^{-3} \mathrm{~mol} \mathrm{dm}^{-3}$. The contribution fraction of this sea-salt source $A$ is $69.3 \%$ as a whole, but those of $B-F$ are very small (8.8 $2.2 \%$ ) (See Table 2, the 6-factor case of Akita). We have found that the precipitations of Akita are mainly dominated by the sea-salt source $A$. The seasonal change of this sea-salt source is high in winter (Dec. Feb.), because it is brought by the winter wind. The winter wind, a typical northwest monsoon observed at Akita, blows from China to Akita over the Sea of Japan.

Generally, scientists say that the $\mathrm{pH}$ of the precipitation of winter is lower than that of summer in the area close to the Sea of Japan. Figure 5 shows the trend; namely, the pH distribution of precipitations of Akita are gathering around pH 4.5 from December to February. This acidic source seems to be ascribed to the sulfuric acid predominant source B with a contribution fraction $8.8 \%$; it shows high contributions at winter. These sulfuric acids seem to have their origin at China, and seem to be brought to Akita by the winter monsoons, too.

The pollutant source $\mathrm{C}$ has a bad ion-balance value 0.1906 , in which sodium ion is predominant. We have receiving an Asian long-range eolian dust referred to as "kosa" in Japan. ${ }^{17}$ Some kinds of dust contain sodium ion; and the major anions are carbonate ion and silicate ion, which have not been measured in this study. The poor value of the ion-balance may be due to these anions. This source shows a contribution fraction $5.4 \%$. The fact that this source has also high contributions in winter supports the conclusion that this source is coming from China across the Sea of Japan, too.

When six factors are assumed, we get two kinds of acidic pollutant source $B$ (sulfuric acid predominant) and $F$ (nitric acid predominant). As is mentioned above, the sulfuric acid predominant source $B$ has high contributions during winter; but some precipitations of June of 1993 have high contributions of this source B. In this summer season, we have little contribution from the sea- 


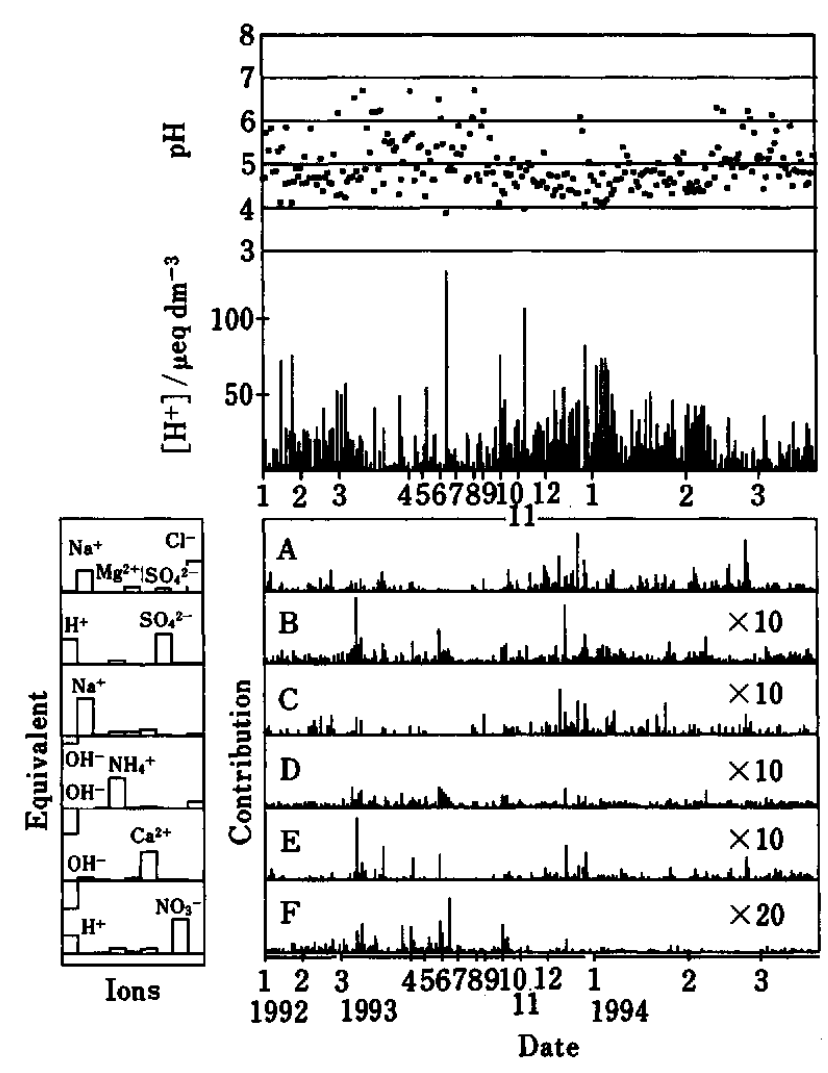

Fig. 5 Chemical compositions of six pollutant sources and their contributions to precipitations collected at Akita $(\mathrm{Ak}+\mathrm{Yz})$. See the text as to the scales of compositions and contributions. Also, refer to Table 2, the 6-factor case of Akita.

salt source. Thus such sulfuric acid may be ascribed to domestic origin. Another acidic source, nitric acid predominant source $\mathrm{F}$, has very small contribution fraction $(2.2 \%)$, but has relatively high contributions in summer (April to June); thus such nitric acid is ascribed to domestic origin.

The other two pollutant sources are alkaline sources containing $\mathrm{OH}^{-}$: $\mathrm{D}(4.7 \%)$ and $\mathrm{E}(4.1 \%)$. The calcium predominant $E$ shows its high contributions in winter and March. The ammonium predominant $D$ has high contributions at March to June of 1993; it may be ascribed to bio-origin.

As a conclusion, the data-set Akita shows domestic emission of sulfuric acid (B) and nitric acid (F); but the contributions of the sulfuric acid brought by the winter monsoons are very large. Thus, the area Akita facing to the Sea of Japan has low $\mathrm{pH}$ precipitations in winter.

As seen above, the grouping of the pollutant sources in precipitations and the numerical evaluation of their contributions give useful information to interpret the origin of the pollution. Especially, we have found that two kinds of pollutant sources are participating in the lowering of the $\mathrm{pH}$ of the precipitations of Hyogo and
Akita: Source-1) the acidic source with sulfuric acid as predominant component, which comes over the Sea of Japan from China by northwest monsoon (winter monsoon), Source-2) the acidic source with sulfuric acid and nitric acid, which is emitted domestically. The seasonal change of acidity of the precipitation of Japan depends upon the amounts of these two contributions: the areas close to the Sea of Japan (e.g. Akita) has low $\mathrm{pH}$ precipitations at winter due to high contribution of Source-1; and the areas close to the Pacific Ocean (e.g. Hyogo) has low $\mathrm{pH}$ precipitations at summer due to high contribution of Source-2.

This work was supported by Grant-in-Aid (No. 07640806) for Scientific Research from the Ministry of Education, Science, Sports and Culture of Japan.

\section{References}

1. H. Hara, E. Ito, T. Katou, Y. Kitamura, T. Komeiji, M. Oohara, T. Okita, K. Sekiguchi, K. Taguchi, M: Tamaki, Y. Yamanaka and K. Yoshimura, Bull. Chem. Soc. Jpn., 63, 2691 (1990).

2. M. Matsumoto, N. Ueda and T. Itano, J. Jpn. Soc. Air Pollut., 20, 218 (1985).

3. R. J. Vong, H.-C. Hansson, H. B. Ross, D. S. Covert and R. J. Charlson, J. Geophys. Res., 93, 1625 (1988).

4. H. A. Bridgman, Atmos. Environ., 26A, 2401 (1992).

5. P. Zhang, N. Dudley, A. M. Ure and D. Littlejohn, Anal. Chim. Acta, 258, 1 (1992).

6. H. A. Khwaja and L. Husain, Atmos. Environ., 24A, 1869 (1990).

7. C. J. Kessler, T. H. Porter, D. Firth, T. W. Sager and M. W. Hemphill, Atmos. Environ., 26A, 1137 (1992).

8. T. Ozeki, K. Koide and T. Kimoto, Environ. Sci. Technol., 29, 1638 (1995).

9. JEA, "A Mannual for Acid Precipitation Monitoring", 1990; 2nd ed., Japan Environment Agency, Tokyo, 1990.

10. T. Ozeki, H. Kihara and S. Hikime, Anal. Chem., 59, 945 (1987).

11. T. Ozeki, H. Kihara, S. Hikime and S. Ikeda, Anal Sci., 3, 285 (1987)

12. T. Ozeki, H. Kihara and S. Ikeda, Anal. Chem., 60, 2055 (1988).

13. E. R. Malinowski and D. G. Howery, "Factor Analysis in Chemistry", 1st ed., p. 49, Wiley, New York, 1980.

14. H. G. Campbell, "An Introduction to Matrices, Vectors, and Linear Programming", 2nd ed., p. 201, Prentice-Hall, 1977.

15. T. Machida and N. Kojima, "Personal Computer BASIC, Numerical Calculation II" (in Japanese), p. 178, Tokai University Press, Tokyo, 1987.

16. P. Anttila, P. Paatero, U. Tapper and O. Järvinen, Atmos. Environ., 29, 1705 (1995).

17. K. Inoue, Y. F. Zhang and T. Naruse, Jpn. J. Soil Sci. Plant Nutr., 65, 619 (1994).

(Received March 8, 1996)

(Accepted February 12, 1997) 